\title{
Políticas Educacionais e Psicologia: diálogos para incluir alunos com necessidades educativas especiais
}

\section{Educational Policies and Psychology: dialogues to include students with special educational needs}

\author{
Sônia da Cunha Urt, Célia Beatriz Piatti; Joelci Mora Silva, Solange Izabel Balbino \\ Faculdade de Educação, Universidade Federal de Mato Grosso do Sul, Brasil
}

\begin{abstract}
Resumo
O principal objetivo deste trabalho é propor reflexões acerca das políticas para educação inclusiva de alunos(as) com necessidades educativas especiais. Provém do estudo de dissertações defendidas entre 2003-2017 nos cursos de mestrado em Psicologia em Mato Grosso do Sul, e compõe os estudos da pesquisa "Políticas Educacionais e Formação: Produção, Projetos e Ações de Educação e Psicologia". A Teoria Histórico-cultural embasou as análises realizadas. Consideramos que a interface entre Psicologia e Educação auxilia no estabelecimento e manutenção dos direitos de todos(as) ao atendimento de específicas necessidades educacionais, já que entende a educação como principal atividade para o desenvolvimento cognitivo.

Palavras-chave: políticas, integração escolar, psicologia educacional
\end{abstract}

\begin{abstract}
The main objective of this work is to propose reflections on the policies for inclusive education of students with special educational needs. It comes from the study of defended dissertations between 2003-2017 at Psychology Masters Courses in Mato Grosso do Sul, and composes studies of the research "Educational Policies and Training: Production, Projects and Education/Psychology Actions". The Historical-cultural theory was used in analyzes. We consider that the interface between Psychology and Education helps the establishment and maintenance of the rights of all to the attendance of specific educational needs, since it understands the education as main activity for the cognitive development.

Keywords: policits, School Integration, educational psychology
\end{abstract}

\section{Introdução}

Ao considerar o atual contexto, destaca-se que o Brasil passa por profundas transformações nas áreas científicas, tecnológicas, sociais, econômicas, culturais e políticas. Tais mudanças influenciam e são refletidas pelas políticas educacionais, estabelecidas e propostas, que devem primar pela garantia de uma educação de qualidade para todos(as), diante de um cenário de inconstâncias e desigualdades, onde ficam explícitos quão diversos e significativos são os problemas enfrentados atualmente pelas escolas brasileiras na tarefa de educar.
Partindo desse entendimento, consideramos que são essenciais políticas educacionais, programas e ações que contemplem suas dificuldades e especificidades. Essas medidas devem visar o atendimento das necessidades individuais e coletivas para concretizar direitos garantidos em lei. Considerados a importância e o impacto desse tema, nos dedicamos a investigar as políticas e ações educacionais em diálogo com as questões inerentes ao campo da Psicologia Escolar e Educacional.

Com essa finalidade, o Grupo de Estudos e Pesquisa em Psicologia e Educação (GEPPE) realiza desde 2015 a pesquisa que se intitula "Políticas Educacionais e Formação: Produção, Projetos e Ações de Educação e Psicologia", que se subdivide nos eixos Educação e Psicologia.

O trabalho que ora apresentamos advém do subprojeto “Análise das produções e projetos dos pesquisadores e pesquisadoras dos programas e nos programas de pós-graduação de Educação e de Psicologia em Mato Grosso do Sul" do eixo Psicologia. Tem como principal objetivo propor reflexões acerca das políticas para educação inclusiva de alunos(as) com necessidades educativas especiais, a partir dos estudos efetuados em dissertações, que foram defendidas entre os anos de 2003 e 2017, nos cursos de mestrado em Psicologia no estado de Mato Grosso do Sul.

O referencial da Teoria Histórico-cultural embasou a proposição da pesquisa e sustentou as análises e discussões realizadas, justaposto às contribuições dos estudiosos da Educação e das Políticas Educacionais.

A escrita do trabalho em tela foi dividida em três momentos: "Psicologia Educacional e Educação inclusiva" é o primeiro momento onde foram expostos os pressupostos norteadores do trabalho acerca da interlocução das áreas Psicologia Educacional e Educação inclusiva direcionada às necessidades educativas especiais; em "Metodologia" tiveram lugar a caracterização metodológica e a apresentação do percurso da investigação da qual esse trabalho deriva; no terceiro momento "Resultados e discussão" foram realizadas as análises e as reflexões teóricas provenientes dos achados da pesquisa aqui apresentada. 


\section{Psicologia Educacional e Educação inclusiva}

Duas questões se destacam quando falamos a respeito da educação inclusiva ou especial: a quem essa inclusão se refere de fato e quais parâmetros de normalidade para que determinados indivíduos sejam considerados especiais? Acerca delas, Vigotski (2003) afirma que o conceito de normalidade consiste numa noção científica difícil e indeterminada:

Esses limites não existem em nenhuma parte e, nesse sentido, a norma representa o conceito meramente abstrato de certa magnitude média dos casos mais frequentes de um fenômeno e, nos fatos, não se encontra em forma pura, mas sempre mesclada com algumas formas anormais. Por isso, não existem limites precisos de nenhuma índole entre o comportamento normal e o anormal. (Vigotski, 2003, p. 257).

Desse modo, precisamos perceber as diferenças pontuais entre os sujeitos como não limitante para sua educação e compreender que as relações construídas dentro de um sistema de educação inclusiva não prejudicam o processo de ensino e aprendizagem. Ao contrário, possibilitam a constituição de novas relações de aprendizagem, tanto para o indivíduo considerado especial quanto para o "normal".

Para Vigotski (2003) os métodos de ensino utilizados com essas crianças devem ser, praticamente os mesmos que são utilizados com os demais indivíduos, respeitando o seu tempo e suas especificidades. Entendemos que as oportunidades educacionais ofertadas, independente da excepcionalidade do(a) aluno(a), contribuem significativamente com seu desenvolvimento ao possibilitar aquisição e apropriação do conhecimento científico.

Num contexto de educação inclusiva, oferecer condições necessárias para que essa apropriação seja possível é imprescindível e torna o sistema educacional apropriado para o acolhimento desses sujeitos. Nesse sentido, sob a perspectiva psicológica, o método de ensino adequado possibilita o desenvolvimento de suas potencialidades independente das barreiras cognoscitivas aparentes: “[...] é sumamente importante não isolar essas crianças em grupos fechados especiais, mas exercitar o mais amplamente possível sua comunicação com os demais." (Vigotski, 2003, p. 262).

Também é importante perceber que entre as crianças com necessidades educativas especiais existem diferenças específicas e não se pode incluir toda a diversidade de alunos(as) numa mesma concepção de deficiência. Cada um tem suas particularidades, o que os torna diferentes entre si, ampliando a discussão acerca do tema e do acolhimento a essa população.

Portanto, ao observarmos tais considerações acerca do processo de ensino e aprendizagem e suas relações com a educação inclusiva, sob o olhar da psicologia, entendemos que ambos se completam e, corroboram para o acesso de alunos(as) denominados(as) especiais às escolas e à educação comum.

Como afirma Vigotski (2003), as dificuldades se apresentam nas práticas educativas que devem ser repensadas e exercidas atendendo a individualidade dos alunos(as), utilizando um método que compense as deficiências, adapte as técnicas e resolva as questões reduzindo as dificuldades o máximo possível para todos os envolvidos nesse processo.

Deste modo o propósito primeiro da educação inclusiva, deve ser tornar a escola um espaço possível para todos os alunos(as), independente de condições educativas pessoais e, em seguida, possibilitar a aprendizagem considerando as especificidades de cada aluno(a). Apesar da complexidade do tema, é importante que o entendimento de que incluir exige certas condições específicas ao mesmo tempo em que implica receber a todos de maneira geral, sobressaia e se consolide.

Dazzani (2010) afirma que para que a psicologia educacional possa participar ativamente do processo de inclusão escolar é necessário compreender a escola como um espaço vivo e diversificado, habitado por diferentes indivíduos.

A educação inclusiva deve permitir a todas as crianças a convivência no mesmo ambiente possibilitando a troca de experiências, o que contribui para a ampliação das relações sociais entre sujeitos diferentes.

Urt (2000) revela que parte das críticas à presença de uma psicologia educacional advém das formas de sua utilização. Apontam o seu caráter psicologizante e ideológico que a distanciaria dos conteúdos e das práticas escolares, gerando a descontextualização do sujeito em seu ambiente.

Concordamos com seu posicionamento quando discute as deficiências geradas por uma psicologia positivista que cumpre apenas função de adaptar os indivíduos à sociedade, incorrendo no erro de parecer uma psicologia neutra. Acreditamos na possibilidade de uma psicologia educacional fundamentada no próprio sujeito que não trate somente de discutir as contradições entre o homem e a sociedade.

Assim, entendemos que parte do trabalho entre a psicologia e a escola, num contexto de educação inclusiva, seja preservar a diversidade apresentada e possibilitar o atendimento às necessidades especiais de cada estudante. Será preciso oferecer oportunidades específicas afim de que o acesso ao conhecimento os torne iguais.

Vigotski (1997) afirmava que a defectologia era considerada uma área de menor importância dentro da pedagogia, porém defendia a tese de que uma criança não pode ser considerada menos capaz de se desenvolver do que outra devido às suas deficiências. Essas crianças, somente, apresentam um desenvolvimento diferente, o que requer um método de ensino apropriado.

$\mathrm{Na}$ prática, a defectologia também escolheu o caminho mais fácil, do número e da medida, tomando consciência de si como uma pedagogia menor. Enquanto na teoria o problema se reduzida a um desenvolvimento quantitativamente limitado e de proporções menores, na prática, naturalmente, se promoveu um ensino reduzido e mais lento. (Vigotski, 1997, pp. 11-12, tradução nossa). 
Para Vigotski (2011), há que se conduzir essas crianças por caminhos indiretos ou alternativos para o seu pleno desenvolvimento. Caminhos que devem ser culturalmente criados quando a impossibilidade de trilhar o caminho direto for percebida. $\mathrm{O}$ aspecto fundamental para essa construção é considerar que, para o desenvolvimento das funções psicológicas superiores é indispensável que sejam detectadas as necessidades individuais, ou seja, a educação deve despertar o interesse de alunos(as) (Vigotski, 2003), independente de sua deficiência para que o desenvolvimento aconteça.

Numa perspectiva de educação inclusiva, a psicologia deve contribuir para o processo de desenvolvimento humano por meio da aquisição e apropriação do conhecimento, oferecendo meios para resolver quaisquer problemas que venham a ocasionar a segregação dentro das escolas.

\section{Metodologia}

Para identificação e análise das referidas produções de pesquisadores dos/nos programas de Pós-graduação de Educação e de Psicologia em Mato Grosso do Sul, que tomaram como objeto de estudo as políticas educacionais na interface com a Psicologia, foi realizada pesquisa com abordagem qualitativa dos resultados, por promover uma aproximação fundamental entre sujeito e objeto. É caracterizada, ainda, como bibliográfica, de cunho documental, do tipo estado do conhecimento.

A justificativa dessa escolha coaduna com as impressões de Soares e Maciel, ao pontuarem a importância científica das pesquisas que investigam o estado do conhecimento dos temas que serão aprofundados, já que essa clareza: "é necessária no processo de evolução da ciência, na identificação de duplicações ou contradições e na determinação de lacunas ou vieses." (Soares; Maciel, 2000, p. 9).

Sua relevância e sua importância são referendadas para a análise de um fenômeno, por proporcionar ao pesquisador as necessárias aproximações com as investigações científicas concluídas, acerca dos temas e assuntos sobre os quais se pretende direcionar o olhar.

\section{Delineamento da pesquisa}

A pesquisa "Políticas Educacionais e Formação: Produção, Projetos e Ações de Educação e Psicologia", que subsidia esse trabalho, conta com cinco subprojetos que compõem os eixos Educação e Psicologia, assim distribuídos:

O eixo Educação abarca as seguintes investigações: 1) o impacto da política do PIBID de fomento à docência; 2) a formação continuada de professores(as) do Ensino Médio no âmbito da educação integral e 3) a constituição do(a) professor(a) leitor na licenciatura de Educação do Campo- PRONACAMPO.

No eixo Psicologia são estudadas: 1) as produções e projetos dos/nos programas de pós-graduação de Educação e de Psicologia em Mato Grosso do Sul, que tomaram como objeto de estudo as políticas educacionais e a área da Psicologia, evidenciando dessa forma o lugar da Psicologia nas políticas públicas, suas ações e interlocuções; 2) a formação do profissional da
Psicologia para atuar na interface com a Educação em Mato Grosso do Sul

As análises que aqui terão lugar provieram do primeiro subprojeto do eixo Psicologia, ainda em andamento, e se intitula "Análise das produções e projetos dos pesquisadores e pesquisadoras dos programas e nos programas de pós-graduação de Educação e de Psicologia em Mato Grosso do Sul”.

Foram pesquisadas as dissertações dos cursos de mestrado em Psicologia da Universidade Católica Dom Bosco (UCDB) e da Universidade Federal de Mato Grosso do Sul (UFMS), ambos funcionando na cidade de Campo Grande-MS, defendidas entre os anos de 2003 e 2016, sendo esses os únicos cursos de Pós-graduação em Psicologia em funcionamento no estado.

As buscas nas páginas eletrônicas desses cursos disponíveis na internet foram efetivadas entre os meses de maio e agosto de 2016, constituindo um inventário de duzentas e vinte e nove dissertações. Dessas, foram selecionados para análise, até o momento, vinte e oito trabalhos, por tomarem como objeto de estudo as políticas educacionais (perfazendo 12,22\% do total levantado).

Foi usada a Análise de Conteúdo como técnica para a compreensão e estudo dos dados coletados.

As dissertações selecionadas foram agrupadas em seis categorias de análise, definidas a priori, a saber: Políticas intersetoriais; Políticas de melhoria da educação; Políticas de atendimento à diversidade; Políticas para educação inclusiva; Políticas de formação e atuação do psicólogo escolar e Políticas de formação de professores(as).

Resultados e discussões que serão exibidos a seguir considerou trabalhos que compuseram a categoria "Políticas para educação inclusiva". Integraram essa categoria trabalhos que investigaram e/ou discutiram a política de inclusão escolar, geral ou de um segmento específico (por exemplo surdos, altas habilidades e superdotação, deficiência intelectual, dentre outros) bem como atendimentos educacionais em geral.

\section{Resultados e discussão}

\section{Panorama geral}

Apresentamos abaixo (Tabela 1) os percentuais de incidência das dissertações analisadas separados por eixos. Essa informação, embora não tenha a finalidade de definir a importância dos temas abordados por cada um dos eixos, já que todos possuem notória relevância, revela um desenho que ajudará a estabelecer diretrizes para as análises e discussões que seguirão.

Tabela 1

Percentuais de incidência das dissertações por Categoria

\begin{tabular}{lcc}
\hline Categorias & Qtd & $\%$ \\
\hline Políticas intersetoriais & 14 & 48,28 \\
Políticas de melhoria da educação & 7 & 24,14 \\
Políticas de atendimento à diversidade & 3 & 10,34 \\
Políticas para educação inclusiva & 2 & 6,89 \\
Políticas de Formação psicólogo escolar & 1 & 3,45 \\
Políticas de formação de professores & 1 & 3,45 \\
\hline
\end{tabular}


Apenas 6,89\% dos trabalhos analisados consideraram a educação inclusiva, sinalizando para um baixo interesse acerca do tema, ao compararmos com a incidência de dissertações que trataram acerca das políticas intersetoriais $(48,28 \%)$. Tal análise reforça a necessidade de incentivar reflexões e inquietações acerca da inclusão de estudantes com necessidades educativas especiais, principal propósito da discussão teórica a seguir.

\section{Educação inclusiva: sentido educativo e social}

Entendemos que a educação é um direito de todos e para todos. É um direito constitucional, que prevê que todos tenham acesso a uma educação de qualidade. Nessa perspectiva, a escola como espaço de socialização tem uma tarefa a cumprir com as diferenças que existem em cada sujeito de forma a incluí-los e não segregá-los.

Não basta garantir o direito instituído em política nacional, mas é preciso criar condições para que todos que adentram a escola possam permanecer e continuar seus estudos com sucesso. Ressaltamos que discutir as necessidades educativas especiais é importante não apenas para as crianças com deficiências, mas também para as que apresentam dificuldades de aprendizagem. Portanto, é necessário pensar a escola no contexto de inclusão e os(as) professores(as) como aqueles que se deparam diariamente com as necessidades dessas crianças.

Conforme analisa Sacristán a inclusão é defendida como processo social, histórico, ético e político. Respeito às diferenças é uma forma de conceber a educação como fator de inclusão. Segundo Sacristán (2001, p.66) podemos considerar que, "o potencial que a educação desempenha para todos é da inclusão.”.

Uma das questões que nos levam a pensar a inclusão na escola está na perspectiva de pensar: o que é inclusão? Se considerarmos em termos gerais podemos dizer que significa abranger, agregar, integrar e tantas outras acepções que direcionam para o sentido de inserir algo ou alguém em determinada situação ou lugar. Portanto, cabe refletir sobre como acontece essa inclusão de crianças e jovens com necessidades educativas especiais na escola de ensino regular. Quem são os(as) professores(as)? O que pensam? Como atuam e como entendem os processos de atuação frente às crianças com necessidades educativas especiais?

Concordamos com Sacristán quando escreve que [...] o que devem ser e como devem agir os professores depende de considerações sobre a sua formação pedagógica. Sua bagagem cultural, suas qualidades pessoais, seus status social, as condições e as regulações do seu trabalho, sua ética profissional, a percepção que têm de si mesmo como profissionais ou educadores. Tudo isso define suas ações e qualidade de seu ensino. (Sacristán, 2001, p.121).

Compreendemos que o(a) professor(a) tem um papel relevante na condução das atividades que envolvem os(as) alunos(as), mas é preciso compreender o que sabem sobre como conduzir esses processos que incluem as crianças com necessidades educativas especiais.
Ao considerar a inclusão como possibilidade de promover mudança na organização escolar, altera-se a ideia de que o(a) aluno(a) deve se adaptar a escola. Um sistema escolar inclusivo é aquele que consegue superar o desafio de compreender que qualquer que seja a deficiência da criança ou do jovem o importante é que eles tenham sucesso em sua aprendizagem. Frente a essa questão, destacamos dois trabalhos que integram a pesquisa, por darem relevância a aspectos importantes sobre os(as) professores(as) em relação a inclusão.

A dissertação intitulada "Inclusão do aluno com deficiência mental: experiências psicossociais dos(as) professores(as) da escola pública" traz a importância de refletir sobre os(as) professores(as) e quais as representações que eles têm da criança com necessidades especiais. Todos os entrevistados(as) foram professores(as) de escola públicas. Foram estabelecidos como critérios que tivessem vivenciado a experiência da inclusão escolar de pelo menos um(a) aluno(a) nos últimos cinco anos e que não tivessem filhos com qualquer tipo de deficiência, uma vez que considerava que esse último fator poderia intervir significativamente na interação entre o professor(a) e o aluno(a) com deficiência.

Em sua investigação, a pesquisadora analisa que, os(as) professores(as) entrevistados(as)

[...] sentem-se descrentes das possibilidades desses alunos em avançar nos estudos, apresentam dificuldades de reconhecer $o$ significado da proposta inclusiva, não se consideram preparados para o ensino e o acompanhamento inclusivo e percebem que em sala de aula a relação com as crianças é permeada por sentimentos diversos como a rejeição, a piedade, o amor, a culpa e a estigmatização. (Tannous, 2004, p.5).

Segundo a pesquisadora, esses sentimentos quando transferidos para a situação de aprendizagem dos alunos(as) com deficiência mental, podem e muitas vezes resultam em forte indício de preconceito para com esses alunos(as).

Consideramos que a descrença, a rejeição, a piedade, o amor, a culpa, entre outros, podem representar sentimentos que afloram devido a falta de compreensão em relação à deficiência e/ou dificuldade da criança que o(a) professor(a) não consegue entender e portanto, não se sente em condições de realizar o seu trabalho junto a essas crianças. Depreende-se que nessa situação cabe indagar: o que significa a inclusão dessas crianças e jovens na escola de ensino regular? Qual é o papel dos(as) professores(as) nessa empreita?

O Plano Nacional de Educação aponta a necessidade e o dever das instituições de ensino superior, inserir em suas licenciaturas, disciplinas específicas para contribuir na formação de profissionais qualificados para acompanhar o processo de ensino e aprendizagem dessas crianças e jovens com necessidades especiais.

Os(as) professores(as) necessitam de constantes acompanhamentos e, por isso, as políticas públicas devem oferecer programas de capacitação para que os(as) professores(as) entendam o seu papel nessa tarefa 
de inclusão, para beneficiar os(as) alunos(as) com necessidades especiais e os demais para que reconheçam também o seu papel como sujeito social nesse processo.

Em outro trabalho analisado "As influências da equitação terapêutica no desenvolvimento de crianças e adolescentes com transtorno de déficit de atenção/hiperatividade", a pesquisadora utiliza-se de um método de Equoterapia/Equitação Terapêutica, aliado à prática esportiva, que estimula aspectos relacionados à atenção, capacidade de concentração e desempenho escolar, importantes para o desenvolvimento de crianças e adolescentes com Transtorno de Déficit de Atenção e Hiperatividade (TDAH).

O objetivo foi reunir informações específicas sobre o participante em ambiente escolar, para tanto, entrevistou professores(as) da disciplina de Língua Portuguesa, cuja carga horária é maior possibilitando um contato maior entre docentes e discentes. Para a pesquisadora no processo de aprendizagem o TDAH compromete o rendimento escolar, pois há dificuldades que interferem no processo de concentração, dentre outras questões que propiciam o sucesso na aprendizagem.

A pesquisadora conclui nesse estudo, a partir do conteúdo trazido pelas professoras entrevistadas que, após intervenção, houve melhoras para os participantes no que se refere ao comportamento em sala de aula, a cooperação em atividades de classe, a socialização, o respeito aos colegas e aos(as) professores(as), a demonstração de afeto, a organização e a disciplina, bem como o cuidado com o seu material, assimilação às normas da sala de aula, escrita, leitura e raciocínio lógico, memorização, interesse em aprender, maturidade e expressão de suas emoções. Além disso, estimulou-se também, a criatividade da criança, favorecendo a criação de novas formas e adaptações na resolução de problemas e na aprendizagem.

A partir dessa análise encontramos na meta 4 do plano Nacional de Educação que aponta a necessidade de universalizar, para a população de 4 (quatro) a 17 (dezessete) anos com deficiência, transtornos globais do desenvolvimento e altas habilidades ou superdotação, o acesso à educação básica e ao atendimento educacional especializado, preferencialmente na rede regular de ensino, com a garantia de sistema educacional inclusivo, de salas de recursos multifuncionais, classes, escolas ou serviços especializados, públicos ou conveniados.

A despeito da escola, nesse sentido, entendemos que é o meio que se configura como espaço de inclusão, de socialização que promove a interação e, portanto, lugar de reconhecimento das diferenças e de possibilidades de avanços no desenvolvimento integral de sujeitos singulares e suas necessidades nesse espaço que é universal.

\section{Considerações possíveis}

Consideramos que a interface entre Psicologia e Educação, propicia olhares especializados por meio dos quais se torna possível referendar o estabelecimento e a manutenção dos direitos de todos(as) para o atendimento de suas específicas necessidades educacionais, uma vez que entende a educação como principal atividade para o desenvolvimento cognitivo.

Os trabalhos analisados evidenciam a importância da ampliação de estudos com enfoque nas necessidades educativas especiais, para que haja um direcionamento específico e embasado nas políticas de formação docente e ações voltadas para área de educação, garantindo dessa forma os direitos de acesso à educação pública de qualidade no Brasil, e possibilitando a permanência e a conclusão dos níveis de ensino que a compõem.

Ao trazer suas representações à tona, docentes demonstram dificuldades na compreensão do processo de inclusão, o que nos permite avaliar que a simples inserção de alunos(as) com necessidades educativas especiais na escola regular não significa inclusão.

É, portanto, necessário pensar que a inclusão de crianças e jovens com necessidades educativas especiais exige alterações nos sistemas de ensino, na formação docente, na interface entre educação e psicologia, para que de fato ocorra a inclusão com resultados promissores para o desenvolvimento integral dessas crianças e jovens e que o espaço escolar possa ser realmente ambiente inclusivo.

\section{Referências}

Dazzani, M. V. M.(2010). A psicologia escolar e a educação inclusiva: uma leitura crítica. Revista Psicologia, Ciência e Profissão, n. 30, v. 2, p. 362375. Disponível

em: http://pepsic.bvsalud.org/pdf/pcp/v30n2/v30n2a11.pdf Acesso em 08 de julho de 2017.

Escobar, C. S.(2004) As influências da equitação terapêutica no desenvolvimento de crianças $e$ adolescentes com transtorno de déficit de atenção/hiperatividade. 244f. Dissertação (Mestrado em Psicologia). Universidade Católica Dom Bosco, Campo Grande, Brasil. Disponível em: http://site.ucdb.br/public/md-dissertacoes/8204-as-infl uencias-da-equitacao-terapeutica-no-desenvolvimento -de-criancas-e-adolescentes-com-transtorno-de-deficit -de-atencao-e-hiperatividade.pdf Acesso em: 10 jul. 2017.

Sacristán, G. J. (2001). A educação obrigatória: seu sentido educativo e social; tradução: Jussara Rodrigues. Porto Alegre: ARTMED editora Ltda.

Soares, M; Maciel, F. (2000). Alfabetização. Brasília: MEC/Inep/Comped, (Série Estado do Conhecimento, $1)$.

Tannous, G. S. (2004) Inclusão do aluno com deficiência mental: experiências psicossociais dos(as) professores(as) da escola pública. Campo Grande, Brasil.. 185f. Dissertação (Mestrado em Psicologia). Universidade Católica Dom Bosco. Disponível em: http://site.ucdb.br/public/md-dissertacoes/7745-inclus ao-do-aluno-com-deficiencia-mental-experiencias-psi cossociais-dos-professores-da-escola-publica.pdf Acesso em: 10 jul. 2017.

Urt, S. C. (2000). Psicologia e Educação: uma relação possível? In. URT, S. C. (org.) Psicologia e Práticas Educacionais. Campo Grande: Editora UFMS. 
Vigotski, L. S.(2003). Psicologia Pedagógica. São Paulo: Artmed. (Schilling, C. Trad.).

Vigotski, L. S. (2011). A defectologia e o estudo do desenvolvimento e da educação da criança anormal. Revista Educação e Pesquisa, São Paulo, v. 37, n. 4, pp. 861-870, dez.. Disponível em: http://www.scielo.br/scielo.php?script=sci_arttext\&pi $\mathrm{d}=\mathrm{S} 1517-97022011000400012$ http://dx.doi.org/10.1590/S1517-97022011000400012 Acesso em: 08 de jul. 2017.

Vygotski, L. S. (1997). Obras escogidas.. Tomo V. Madrid: Visor.

\section{Agradecimentos}

A pesquisa que permitiu a realização desse trabalho foi financiada pelo Conselho Nacional de Desenvolvimento Científico e Tecnológico - CNPq (Chamada CNPq/ MCTI N 25/2015 Ciências Humanas, Sociais e Sociais Aplicadas), coordenada pela Profa. Dra. Sônia da Cunha Urt. 